\title{
A Two Stepwise Molecular Approach for Rapid Separation of Staphylococcus aureus from other Coagulase Negative Staphylococci
}

\author{
Ezeamagu O. Cajethan ${ }^{1 *}$, Fagade E. Obasola ${ }^{2}$, Smith Stella, I. $^{3}$ and Ogunjobi A. Adeniyi ${ }^{2}$ \\ ${ }^{1}$ Department of Biosciences and Biotechnology, Babcock University, Ilishan, \\ Ogun State, Nigeria \\ ${ }^{2}$ Department of Microbiology, University of Ibadan, Oyo State, Nigeria \\ ${ }^{3}$ Molecular Biology and Biotechnology division, Nigerian Institute of Medical Research, \\ Yaba, Lagos, Nigeria \\ *Corresponding author
}

Keywords

S. aureus, coagulase test, PCR-RFLP.

\section{Article Info}

Accepted:

22 June 2016

Available Online:

10 July 2016

\section{A B S T R A C T}

Staphylococcus aureus is the most important cause of nosocomial and community associated infections as well as the most pronounced species in drug resistance amongst Staphylococcus species. There have been reported cases of inconsistency in presumptive coagulase tests using commercial kits and conventional methods. This study therefore reports a simple, rapid, accurate and cost-effective PCRRFLP-based molecular technique that separates and identifies to species level $S$. aureus from other coagulase negative staphylococci. Fifty clinical isolates of staphylococci previously isolated from various specimens were investigated for their ability to clot blood plasma. Of the 50 clinical isolates, $6(12 \%)$ and $44(88 \%)$ isolates yielded positive and negative results, respectively, for conventional tube coagulase test. The PCR-RFLP supplemented with species-specific primers classified these isolates into three distinct species: S. epidermidis (86\%), S. aureus (12\%) and S. xylosus (2\%). Furthermore, the technique applied in this study classified the isolates into two RFLP patterns representing $S$. aureus and other coagulase negative staphylococci which correlated with coagulase test results. Since coagulase test could be sometimes misleading and inconclusive, this method could be substituted in routine laboratory program.

\section{Introduction}

The genus Staphylococcus is the pathogen of man and animals. Basically, they are classified into two based on their plasma clotting ability; coagulase positive staphylococci and coagulase negative staphylococci (CNS). Staphylococcus aureus is the most important cause of nosocomial and community associated infections as well as most prominent in drug resistance especially with emergence of methicillin-resistant strains (NNIS, 2001; Cooper et al., 2004). It is responsible for many of the human diseases which include folliculitis, impetigo, wound infection, toxin-mediated infections that includes toxic 2 shock syndrome, food poisoning, scalded skin syndrome, pneumonia, bacteremia, 
endocarditis, osteomyelitis, septic arthritis are caused by this group of bacteria. Coagulase negative staphylococci belong to the group of opportunistic pathogens found as normal flora of the skin and mucus membranes in different parts of the body (Einsenstein and Schacchter, 1994; Becker et al., 2014). They were originally assumed to be contaminating clinical samples but were not involved in the primary infection; there is evidence that these bacteria may be responsible for primary infections as a result of increased use of medical in dwelling plastic devices and compromised or immunodepressed patients (Jarvis and Martone, 1994; Kloos and Bannerman, 1994, Becker et al., 2014). It is therefore imperative to identify and separate $S$. aureus from CNS owing to its clinical significance in infectious diseases.

In routine laboratory practice, coagulase production has been the conventional screening test to distinguish $S$. aureus from other staphylococci; since other coagulase positive staphylococci (CPS) such as $S$. hyicus, S. schleiferi subspecies coagulase or intermedius have rarely been found in human infections. However, several reports of inconsistency and inaccuracy in the conventional coagulase test have earlier been documented (Buchanan et al., 1983; Fung et al., 1984; Gill et al., 1984). These reports somehow might have contributed to the improvement of conventional coagulase detection by the development of test kits; Staphaurex (Wellcome), Staphylase (Oxoid), Staphyslide (bioMerieux), Biostaph (Medlabs) and Bacto Latex (Difco) (Flandroisand Carret, 1981; Rossney et al., 1990), but these kits are still not accurate and are not within reach of the both health institutions and local clinics in developing countries as they are expensive. In the light of this, the serological separation of CPS and CNS are largely based on slide and tube coagulation tests which are not reliable due to variability in inoculum size, incubation period and inoculation medium (Davies, 1951; Rossney et al., 1990). Beside, this technique when scarcely done has little relevance as it does not conclusively confirm S. aureus as non-staphylococcal species for example; Pseudomonas aeruginosa and Serratiamarcescens can produce coagulase (Rossney et al., 1990). This study was therefore designed to involve two stepwise molecular approaches that will separate $S$. aureus and CNS as well as identify $S$. aureus to species level using PCR-RFLP double digestion format that can be integrated into routine laboratory program.

\section{Materials and methods}

\section{Isolates}

Clinical isolates from various samples (eyes swab, ear swab, wound swab, tissue aspirates high and vagina swab) that were isolated between 2008 and 2011 under normal routine laboratory practice in University College Hospital Ibadan, Nigeria were used for the study. In all, 50 isolates were used for this study.

\section{Re-isolation procedure MSA}

Media used include Mannitol Salt Agar (MSA) and Tryptone Soy Agar (TSA), Oxoid. All the media were prepared according to the manufacturer's instructions by weighing the specified amount of each medium into $100 \mathrm{ml}$ of distilled water. The media were then autoclaved. The sterilized media were allowed to cool to $45^{\circ} \mathrm{C}$ before dispensing into petri dishes to solidify. The petri plates were kept in refrigerator until when needed. All isolates (stored in $40 \%$ glycerol under $-80^{\circ} \mathrm{C}$ freezer) were streaked on already prepared plates on MSA and 
incubated for 18-24hours. Colonies showing yellow colouration or whitish color were picked and sub-cultured on TSA and incubated at $37^{\circ} \mathrm{C}$ between $18-24$ hours. The sub-cultured organisms were used for subsequent screening.

\section{Catalase test}

Two drops of hydrogen peroxide $\left(3 \% \mathrm{H}_{2} \mathrm{O}_{2}\right)$ were made on a slide and a sterile nonnichrome wire loop was used to pick a colony from overnight growth culture of the test organism and then mixed. An immediate bubbling indicates positive result.

\section{Haemolytic test}

Mueller-Hinton Agar plates were prepared according to the manufacturer's instructions and cooled to $45^{\circ} \mathrm{C}$. Thereafter, $10 \%$ of human blood was added, mixed and were allowed to solidify. After drying, the petri plates were streaked with each organism using a sterile wire loop. The streaked plates were incubated at $37^{\circ} \mathrm{C}$ for between 18 24hrs. Haemolytic and non-haemolytic activities were observed after overnight incubation.

\section{Coagulase test}

Three test tubes were taken and labeled 'test', 'negative control' and 'positive control'. A serial dilution (1 in 10) of human plasma with physiological saline was made. In each tube $0.5 \mathrm{ml}$ of the diluted human plasma was dispensed. Subsequently, the tube labeled test was added with $0.1 \mathrm{ml}$ of overnight broth culture of test bacteria. The tube labeled positive control was also treated with $0.1 \mathrm{ml}$ of overnight broth culture of known $S$. aureus. However, the tube labeled negative control was added with only $0.1 \mathrm{ml}$ of sterile broth. All the tubes were incubated at $37^{\circ} \mathrm{C}$ and observed up to four hours.
Positive result was indicated by gelling of the plasma.

\section{DNA extraction}

The boiling method as described by Perezroth et al., (2001) was applied as follow: Colonies from an overnight culture of the organisms on Tryptone Soya Agar (TSA) were emulsified in $500 \mu 1$ of sterile double distilled water contained in $1.5 \mathrm{ml}$ Eppendorf tubes to give turbidity equivalent to 0.5 McFarland standards. These were transferred into a heating block set at $100^{\circ} \mathrm{C}$ for 10minutes. After boiling, the mixtures were then centrifuged for 5minute at 2400rpm. The supernatant were transferred into fresh sterilized Eppendorf tubes with its purity determined using Nano drop spectrophotometer (3300) and stored at $20^{\circ} \mathrm{C}$ in a refrigerator until when required.

\section{Confirmation of the genus staphylococci}

An aliquot of $2.0 \mu \mathrm{l}$ of DNA suspension was added to $25 \mu$ l of PCR mixture consisting of $5 \mu \mathrm{l}$ standard reaction buffer (Biolabs, England) $\left[20 \mathrm{mM}\right.$ Tris- $\mathrm{HCl}, 1.8 \mathrm{mM} \mathrm{MgCl}_{2}$, $22 \mathrm{mM} \mathrm{NH}_{4} \mathrm{Cl}, 22 \mathrm{mM} \mathrm{KCl}, 0.06 \%$ IGEPL CA-630, 0.05\% Tween 20, pH 8.9)], a 0.2 $\mathrm{mM}$ concentration of each of the four deoxyribonucleoside triphosphates (dATP, dCTP, dGTP, and dTTP), $0.25 \mu$ l of each primers (TstaG422 5'-GGCCGTGTT GAACGTGGTCAAATCA-3' as forward and Tstag765 5'- TIACCATTT CAGTACC TTCTGGTAA-3' as reverse), and $0.125 \mathrm{U}$ of $\mathrm{Taq}$ DNA polymerase. DNA amplification was carried out in a system 9700 thermocycler with the following thermal cycling profiles: Initial denaturation at $94^{\circ} \mathrm{C}$ for 1 minute, denaturation $94^{\circ} \mathrm{C}$ for 30 seconds, annealing $58^{\circ} \mathrm{C}$ for 30 seconds, extension $68^{\circ} \mathrm{C}$ for 1 minute and final extension $68^{\circ} \mathrm{C}$ for 5minutes with a programmable number of 30 cycles. After 
PCR amplification, $10 \mu \mathrm{l}$ of PCR product was removed and subjected to agarose gel electrophoresis $(1.5 \%$ agarose, $1 \mathrm{x}$ Trisborate-EDTA, $100 \mathrm{~V}$, 1hour) to estimate the sizes of the amplification products by comparison with a 100-bp molecular size standard ladder. Following electrophoresis at $100 \mathrm{~V}$ for 1 hour, gels was examined for bands using a photo documentation system (TranUV, illuminator Biorad).

\section{PCR-RFLP by double digestion}

Ten (10) $\mu$ l of each amplified product was mixed $2.5 \mu \mathrm{l}$ of $10 \mathrm{X}$ buffer, $10.5 \mu \mathrm{l}$ of $\mathrm{H}_{2} \mathrm{O}$ and digested with $1.0 \mathrm{U}$ of Hind III and EcoRI restriction enzymes simultaneously. The mixture was incubated at $37^{\circ} \mathrm{C}$ for $1-2$ h. After endonuclease digestion, $10 \mu \mathrm{l}$ of product was removed and subjected to agarose gel electrophoresis (2\% agarose, $1 \mathrm{x}$ TBE, $100 \mathrm{~V}, 1 \mathrm{~h}$ ) to estimate the sizes of the restriction digest by comparison with a 100bp molecular size standard ladder (Biolabs, England). The interpretation criterion for identifying different species was a single band difference.

\section{Results and Discussion}

\section{DNA extraction protocol}

To facilitate quick identification in clinical Microbiology laboratories, a simple DNA extraction procedure was given almost priority. Several DNA protocols exist in literatures where DNA can be extracted from overnight liquid cultures (Tokue et al., 1992; Vannuffel et al., 1995; Giambiagi-de Marval, 1999). However, we adopted the DNA extraction protocol described by Perez-roth et al (2001) with little time modification because it is simple, fast and cheap. This protocol yielded good quality DNA for any PCR amplification procedure.

\section{Correlation of coagulase test with PCR- RFLP}

All the isolates from different clinical sources were confirmed to belong to the genus staphylococci by using genus-specific primers. The genus PCR products after double digestion with restriction endonucleases classified the isolates into two RFLP patterns: A (220-50bp) and B (370bp) representing $S$. aureus and other coagulase negative staphylococci respectively (Fig 1). Of the 50 clinical isolates, $6(12 \%)$ were identified as $S$. aureus and the rest was confirmed to be CNS using species-specific primers (Table 1). All the six S. aureus $(100 \%)$ identified using the PCR-RFLP gave a positive coagulase test and $88 \%$ of the CNS were negative for coagulase test. This tube coagulase test correlated well with this molecular technique.

Experimental evidence of staphylococcal coagulase production in vitro has been shown to be affected by many factors and tube coagulase test results vary depending on the methods used (Buchanan et al., 1983; Fung et al., 1984; Gill et al., 1984; Rossney et al., 1990).

The conventional tube coagulase test correlated with this new technique in this study, probably due to the small sample size of $S$. aureus or as a result of the fact that atypical strains were not encountered. The inconsistency in results of various coagulase tests (conventional and commercial kits) for separating $S$. aureus from $\mathrm{CNS}$ have necessitated some investigators to advocate for an alternative test in addition to coagulase test (Selepak and Witebsky, 1985; Ozen et al., 2011). 
Table.1 Distribution of sample sources, organisms and confirmation of Staphylococci using genus-specific primers

\begin{tabular}{lccl}
\hline Sample source & $\begin{array}{c}\text { No of } \\
\text { isolates }\end{array}$ & $\begin{array}{c}\text { Confirmed with } \\
\text { TstaG442/Tstag765 } \\
\text { primers }\end{array}$ & \multicolumn{1}{c}{ Organisms identified } \\
\hline Semen & 8 & 8 & S. aureus (1), S. epidermidis $(7)$ \\
HVS & 1 & 1 & S. epidermidis (1) \\
Wound & 16 & 16 & S. aureus (3), S. epidermidis $(13)$ \\
Eye & 13 & 13 & S. aureus $(1)$. S. epidermidis $(12)$ \\
Ear & 7 & 7 & S. epidermidis (7) \\
Urethra & 1 & 1 & S. epidermidis $(1)$ \\
skin & 1 & 1 & S. aureus $(1)$ \\
Sputum & 1 & 1 & S. epidermidis $(1)$ \\
Throat & 1 & 1 & S. xylosus $(1)$ \\
Soft tissue & 1 & 1 & S. epidermidis $(1)$ \\
\hline Total & $\mathbf{5 0}$ & $\mathbf{5 0}$ & \\
\hline
\end{tabular}

Fig.1 RFLP patterns after digestion with restriction endonucleases.

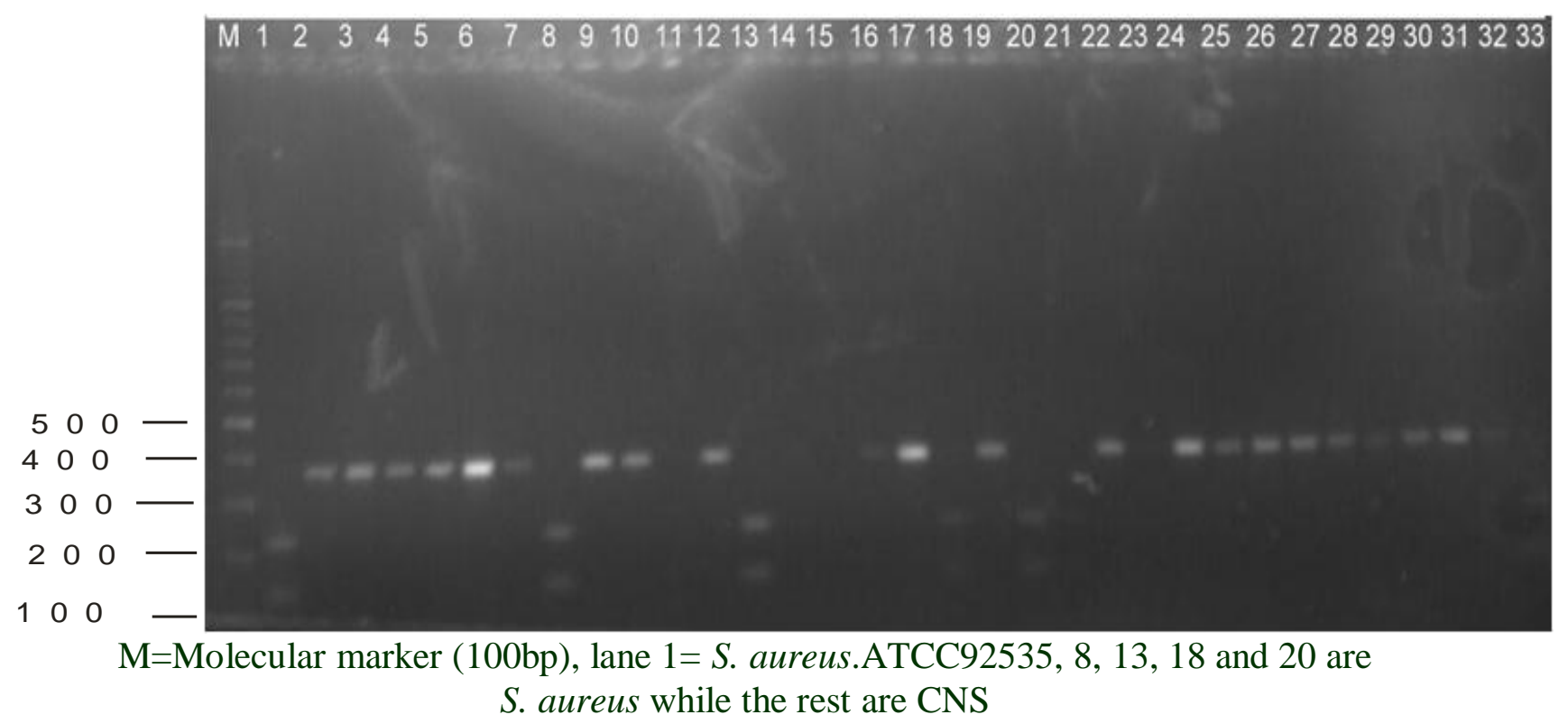

Several publications have reported somehow similar biochemical characteristics of coagulase negative staphylococci to $S$. aureus (Buchanan et al., 1983; Fung et al., 1984) and this as well as other factors might have necessitated PCR-based procedures for discriminating staphylococci using different restriction enzymes and gene targets such as PCR-RFLP ofprotein A coding gene, coagulase gene (Mehndiratta et al., 2009,
Bhati et al., 2014), PCR-RFLP of gap gene (Ghebremedhin et al., 2008). Each of these techniques selects either CPS or CNS. The disadvantages of aforementioned techniques above lie with the fact that when CPS or CNS is fingered as the cause of a particular infection(s), they require more than a pair of primers and one restriction enzyme for complete fingerprinting. Also, more resources and time are required to achieve 
this purpose. However, this current procedure selects both CPS and CNS with different restriction patterns. The technique seems to take advantage of genetic differences between the coagulase and noncoagulase gene sequences rather than the individual species diversity. It is also possible that the CNS either has no restriction sites for endonucleases used or probably that the parts of restriction products were too small to be detected by conventional agarose gel electrophoresis. It is worthy to note that when Hind III restriction endonulease was used alone, no digestion was observed, and it seemed therefore that EcoR1 was responsible for the restriction pattern observed. However, we only reported double digestion that we did. Although, other coagulase positive staphylococci such as S. hyicus, S. schleiferi subspecies coagulanse or intermedius were not available for inclusion to affirm this assumption. Further work is required to clarify this assumption (i.e. genetic differences). Since coagulase test could be sometimes misleading and inconclusive, this method could be substituted for routine laboratory program especially when isolating S. aureus amidst CNS from clinical or other based samples.

\section{References}

Becker, K., Heilmann, C., Peters, G. 2014. Coagulase-Negative Staphylococci Clin. Microbiol. Rev., 27(4): 870-926.

Bhati, T., Nathawat, P., Ahmad, I.M., Kumar, S.S., Yadav, R., Kumar, A.K. 2014. PCR-RFLP of Staphylococcus aureus Coagulase Gene Isolated from Bovine Subclinical Mastitis J. Appl. Microbiol., 8(6): 4711-4714.

Buchanan, A.G., Booth, H., Emery, J. 1983. Coagulase negative Staphylococcus aureus. Clin. Microbiol. News, 5: 144145.
Cooper, B.S., Medley, G.F, Stone, S.P, Kibb1er, C.C, Cookson, B.D, Roberts, J.A, Duckworth, G, Lai, R. and Ebrahim, S. 2004. Methicillinresistant Staphylococcus aureus in hospitals and the community: stealth dynamics and control catastrophes, Proc. Natl. Acad. Sci., 101(27): 223228.

Davies, G.E. 1951. Factors influencing the in vitro production of staphylococcal coagulase. J. Gen Microbiol., 5: 68797.

Einsenstein, B.I., and Schaechter, M. 1994. Biota microbiana normal. Microbiologis. Mecanismo de Las EnfermedadesInfecciosas, 2nd edn. Barcelona, Spain: Panamericana, 3646.

Flandrois, J.P., Carret, G. 1981. Study of the staphylococcal affinity to fibrinogen by passive haemagglutination: a tool for the Staphylococcus aureus identification. ZblBaktHyg 1 AbtOrigA 251:171-6. [PubMed].

Fung, J.C., Kaplan, M.H., Hsieh, H.C., Stephens, A., Tyburski, M. Band Tenebaum, N.I. J. 1984. Two coagulase-variant forms of Staphylococcus aureus isolated from blood cultures. J. Clin. Microbiolol., 20: 115-117.

Ghebremedhin, B., Layer, F, Konig, W and Konig, B. 2008. Genetic classification and distinguishing of Staphylococcus species based on different partial gap, 16S rRNA, hsp60, rpoB, sodA, and tuf gene sequences. J. Clin. Microbiolol., 46: 1019-1025.

Giambiagi-de Marval. 1999. Detection of ileS-2 gene encoding mupirocin resistance in methicillin-resistant Staphylococcus aureus by multiplex PCR. Diagn Microbiol. Infect. Dis., 34: 77-81.

Gill, V.J., Zierdt, C.H., Wu, T.C., Stock, F., 
Pizzo, P.A. and NlacLowry, J.D. 1984. Comparison of lysis-centrifugation with lysis-filtration and a coniventionalunivented bottle for blood cultures. J. Clin. Microbiolol., 20: 927-932.

Jarvis, W.R., and Martone, W.J. 1994. Predominant pathogens in hospitals infections. J. Antimicrob. Chemother., 29 (Suppl. A), 19-24.

Kloos, W., and Bannerman, T. 1994. Update on clinical significance of coagulase negative staphylococci. Clin. Microbiol. Res., 7: 117-140.

Mehndiratta, P.L., Bhalla, P, Ahmed, A. and Sharma, Y.D. 2009. Molecular typing of methicillin-resistant Staphylococcus aureus strains by PCR-RFLP of spa gene: a reference laboratory Perspective. Indian J. Med. Microbiol., 27(2): 116-22.

NNIS. 2001. National Nosocomial Infections Surveillance System report data summary from January 1992 June 2007, issued. Am J Infect Control.29, $404-421$.

Ozen, N.S., Ogunc, D, Mutlu, D, Ongut, G, Baysan, B.O and Gunseren, F. 2011. Comparison of four methods for rapid identification of Staphylococcus aureus directly from BACTEC 9240 blood culture system. Indian J. Med. Microbiol., 29(1): 42-46.
Perez-Roth, E., Claverie-Martin, F, Villar, J and Mendez- Alverz, S. 2001. Mutliplex PCR for simultaneous identification of Staphylococcus aureus and detection of methicillin and mupirocin resistance. J. Clin. Microbiolol., 39: 4037-41.

Rossney, A.S., English, L.F and Keane, C.T. 1990. Coagulase testing compared with commercial kits for routinely identifying Staphylococcus aureus, J. Clin. Pathol., 43: 246-252.

Selepak, S.T., Witebsky, F.G. 1985. Inoculum size and lot-to-lot variation as significant .variables in the tube coagulase test for Staphylococcus aureus. J. Clin. Microbiolol., 22(5): 835.

Tokue,, Y., Shoji, S, Satoh, K, Watanabe, A and Motomiya, M .1992. Comparison of a polymerase chain reaction assay and conventional microbiologic method for detection of methicillinresistant Staphylococcus aureus. Antimicrob. Agents Chemother., 36: 6-9.

Vannuffel, P., Gigi, J., Ezzedine, H., Vandercam, B., Delmee, M., Wauters, G., Gala. J.L. 1995. Specific detection of methicillin-resistant staphylococcus species by multiplex PCR. J. Clin. Microbiolol., 33: 2864-2867.

\section{How to cite this article:}

Ezeamagu O. Cajethan, Fagade E. Obasola, Smith Stella, I. and Ogunjobi A. Adeniyi. 2016. A Two Stepwise Molecular Approach for Rapid Separation of Staphylococcus aureus from other Coagulase Negative Staphylococci. Int.J.Curr.Microbiol.App.Sci. 5(7): 778-784. doi: http://dx.doi.org/10.20546/ijcmas.2016.507.089 